\title{
Trend in ice moistening the stratosphere - constraints from isotope data of water and methane
}

\author{
J. Notholt ${ }^{1}$, G. C. Toon ${ }^{2}$, S. Fueglistaler ${ }^{3}$, P. O. Wennberg ${ }^{4}$, F. W. Irion $^{2}$, M. McCarthy ${ }^{5}$, M. Scharringhausen ${ }^{1}$, \\ T. Siek Rhee ${ }^{6}$, A. Kleinböhl ${ }^{2}$, and V. Velazco ${ }^{2}$ \\ ${ }^{1}$ Institute of Environmental Physics, University of Bremen, 28334 Bremen, Germany \\ ${ }^{2}$ Jet Propulsion Laboratory, California Institute of Technology, Pasadena, CA 91109, USA \\ ${ }^{3}$ Dept. of Applied Mathematics and Theoretical Physics, University of Cambridge, Cambridge, CB3 OWA, UK \\ ${ }^{4}$ Geology \& Planetary Sciences, California Institute of Technology, Pasadena, CA 91125, USA \\ ${ }^{5}$ Sonoma Technology, Inc., Petaluma, CA 94954, USA \\ ${ }^{6}$ Korean Polar Research Institute, Ansan 426-744, Korea
}

Received: 30 June 2009 - Published in Atmos. Chem. Phys. Discuss.: 12 August 2009

Revised: 14 December 2009 - Accepted: 15 December 2009 - Published: 12 January 2010

\begin{abstract}
Water plays a major role in the chemistry and radiative budget of the stratosphere. Air enters the stratosphere predominantly in the tropics, where the very low temperatures around the tropopause constrain water vapour mixing ratios to a few parts per million. Observations of stratospheric water vapour show a large positive long-term trend, which can not be explained by change in tropopause temperatures. Trends in the partitioning between vapour and ice of water entering the stratosphere have been suggested to resolve this conundrum. We present measurements of stratospheric $\mathrm{H}_{2} \mathrm{O}, \mathrm{HDO}, \mathrm{CH}_{4}$ and $\mathrm{CH}_{3} \mathrm{D}$ in the period 19912007 to evaluate this hypothesis. Because of fractionation processes during phase changes, the hydrogen isotopic composition of $\mathrm{H}_{2} \mathrm{O}$ is a sensitive indicator of changes in the partitioning of vapour and ice. We find that the seasonal variations of $\mathrm{H}_{2} \mathrm{O}$ are mirrored in the variation of the ratio of $\mathrm{HDO}$ to $\mathrm{H}_{2} \mathrm{O}$ with a slope of the correlation consistent with water entering the stratosphere mainly as vapour. The variability in the fractionation over the entire observation period is well explained by variations in $\mathrm{H}_{2} \mathrm{O}$. The isotopic data allow concluding that the trend in ice arising from particulate water is no more than $(0.01 \pm 0.13)$ ppmv/decade in the observation period. Our observations suggest that between 1991 and 2007 the contribution from changes in particulate water transported through the tropopause plays only a minor role in altering in the amount of water entering the stratosphere.
\end{abstract}

Correspondence to: J. Notholt (notholt@uni-bremen.de)

\section{Introduction}

Air enters the stratosphere predominantly through the tropical tropopause, where the cold temperatures limit water vapour mixing ratios to a few parts per million by volume (ppmv) (Brewer, 1949; Holton et al., 1995). Stratospheric water is an important greenhouse gas and plays a major role in the stratospheric chemistry (Brasseur and Solomon, 2005; Forster and Shine, 2002). The reported opposite trends of stratospheric water and tropical tropopause temperatures (Rosenlof et al., 2001; Zhou et al., 2001) suggest that our understanding of processes controlling water entering the stratosphere $\left(\mathrm{H}_{2} \mathrm{O}^{\text {entry }}\right)$ is incomplete. During the last years, our understanding of the processes that control water entering the stratosphere on annual and interannual timescales has improved greatly (Weinstock et al., 1995; Mote et al., 1996; Jensen and Pfister, 2004; Fueglistaler et al., 2005; Randel et al., 2006; Read et al., 2008). However, the reported longterm trends remain unexplained (Rosenlof et al., 2001; Oltmans and Hofman, 1995; Fueglistaler and Haynes, 2005). A major impediment to better understanding is that trend estimates based on different instruments are inconsistent (Randel et al., 2004; Scherer et al., 2008).

The general upward transport across the tropopause is thought to be the consequence of the wave-driven stratospheric circulation, but the degree to which this transport is accounted for by convection that detrains directly into the stratosphere is still under debate (Fueglistaler et al., 2009). Air rising slowly with the wave driven circulation experiences cooling up to the tropopause, leading to cirrus formation and subsequent gravitational removal of the

Published by Copernicus Publications on behalf of the European Geosciences Union. 
ice. Conversely, convection detraining above the level of neutral buoyancy may either have a drying effect (because the temperature of the convective core may be below ambient temperatures), or a moistening effect (because in convective transport water in the condensed phase may greatly exceed that in the vapour phase). The latter effect may be particularly pronounced for convection that detrains above the cold point tropopause, as the detraining air masses mix with a subsaturated environment. In both cases, water may enter the stratosphere not only as vapour, but also in the condensed phase which subsequently evaporates in the stratosphere. Because of the general isotopic enrichment of these ice crystals, water entering the stratosphere as ice would lead to a net enrichment of stratospheric water.

Hence, observations of the isotopic fractionation of water can provide important insight into the processes that control the dehydration as the air passes through the tropical tropopause (Moyer et al., 1996; Kuang et al., 2003; Keith, 2000; Webster and Heymsfeld, 2003). HDO provides a sensitive test of whether ice lofting contributes significantly to the observed variability of $\mathrm{H}_{2} \mathrm{O}$. Since $\mathrm{HDO}$ has a lower vapour pressure than $\mathrm{H}_{2} \mathrm{O}$, the $\mathrm{D} / \mathrm{H}$ ratio in the remaining vapour progressively decreases as water vapour condenses (Johnson et al., 2001). If all condensate were immediately removed from an air mass (so-called Rayleigh fractionation), the $\mathrm{HDO} / \mathrm{H}_{2} \mathrm{O}$ ratio at the tropopause would be about 10 times smaller than that at the surface (Moyer et al., 1996; Keith, 2000), corresponding to $\delta \mathrm{D}=-900 \%$ in the commonly used delta-notation. However, measured values for $\delta \mathrm{D}$ lie between $-300 \%$ and $-700 \%$ (Moyer et al., 1996; Kuang et al., 2003; Johnson et al., 2001; Payne et al., 2007; Nassar et al., 2007; Steinwagner et al., 2007).

The relative difference of isotopic ratios, the delta values, is defined as (Kaye, 1987):

$\delta \mathrm{D}=\frac{(N(\mathrm{D}) / N(\mathrm{H}))_{\text {sample }}}{(N(\mathrm{D}) / N(\mathrm{H}))_{\text {standard }}}-1$

where $N(\mathrm{D})$ and $N(\mathrm{H})$ stands for the number of deuterium and hydrogen isotopes, respectively, and $(N(\mathrm{D}) / N(\mathrm{H}))_{\text {standard }}$ is the isotope ratio of the reference, the Standard Mean Ocean Water (SMOW), equal to $1.5576 \times 10^{-4}$. Eq. (1) in units of the volume mixing ratio reads similarly

$\delta \mathrm{D}=\frac{\left([\mathrm{HDO}] /\left[\mathrm{H}_{2} \mathrm{O}\right]\right)_{\text {sample }}}{\left([\mathrm{HDO}] /\left[\mathrm{H}_{2} \mathrm{O}\right]\right)_{\text {standard }}}-1$

The results of Eqs. (1) and (2) are normally expressed in per mille.

Isotope measurements suggest a significant role of ice for the water budget of air that eventually enters the stratosphere, either by direct convective injection or incomplete sedimentation of in-situ formed cirrus clouds (Moyer et al., 1996; Kuang et al., 2003; Keith, 2000; Webster and Heymsfield, 2003). The partitioning between vapour and ice of water entering the stratosphere is currently unknown, but it has been suggested that the amount of ice directly delivered to the stratosphere increases with time due to the increase of tropospheric aerosol production as a consequence of the Asian industrialization and tropical biomass burning (Sherwood, 2002; Notholt et al., 2005). Such processes could explain the enigmatic long term trend of stratospheric water vapour.

\section{Balloon borne observations}

Here, we make use of remote sensing data from the JPL MkIV balloon borne solar occultation FTIR (Fourier transform infrared) spectrometer (Toon, 1991). The spectra used in this work were collected between 1991 and 2007 from the balloon measuring at $33-40 \mathrm{~km}$ altitude as the sun was rising or setting through the limb of the earth's atmosphere. Observations were performed near $35^{\circ} \mathrm{N}$ and $65^{\circ} \mathrm{N}$. Overall 23 balloon profiles have been analyzed, 15 recorded at $35^{\circ} \mathrm{N}$ and 8 measured around $65^{\circ} \mathrm{N}$. The retrieved volume mixing ratio profiles extend from the middle troposphere to $35 \mathrm{~km}$ in $1 \mathrm{~km}$ steps. The solar occultation measurements provide a very high sensitivity to atmospheric trace species at high vertical resolution at the expense of degraded spatial resolution (400 km in line of sight). The broad spectral coverage of $650-5650 \mathrm{~cm}^{-1}$ allows a large number of different gases to be measured simultaneously in the same air mass. The high spectral resolution of $0.01 \mathrm{~cm}^{-1}$ enables individual spectral lines of the different water and methane isotopes to be distinguished (see supplement http://www.atmos-chem-phys.net/ 10/201/2010/acp-10-201-2010-supplement.pdf).

The measured spectra were analyzed by least squares fitting of calculated spectra to the measured ones. The retrieval was performed to determine the volume mixing ratio (vmr) profiles of $\mathrm{H}_{2} \mathrm{O}$, $\mathrm{HDO}$ as well as the $\mathrm{CH}_{4}$ and $\mathrm{CH}_{3} \mathrm{D}$ necessary for analysis of the isotope budget. We use optimal estimation in the sense that the vmr profiles are retrieved simultaneously for all levels. We did not apply an interspecies constraint of $\mathrm{HDO}$ to $\mathrm{H}_{2} \mathrm{O}$. An inter-species constraint is a good idea when doing a ground-based profile retrieval and the problem is under-determined. In the balloon limb-viewing geometry, the retrieval problem is fully determined and so an a priori $\mathrm{HDO} / \mathrm{H}_{2} \mathrm{O}$ constraint is less useful.

The forward calculation and the fitting were performed with the GFIT algorithm, a line-by-line radiative transfer code developed at JPL (Sen et al., 1996). The spectral data were taken from the HITRAN 2004 data base (Rothman et al., 2005), with recent updates to $\mathrm{H}_{2} \mathrm{O}$ and $\mathrm{HDO}$ (Robert Toth, JPL). Suitable micro-windows for each trace gas and isotope have been selected using an automatic line-finding program (Notholt et al., 2006). For each trace gas and isotope between 10 and 40 separated micro-windows have been analyzed individually. Since these microwindows belong to one measurement, the same atmospheric air path, they are averaged to give one vmr-value. Subsequently, the vmr-data for different altitudes (different spectra) have been averaged 


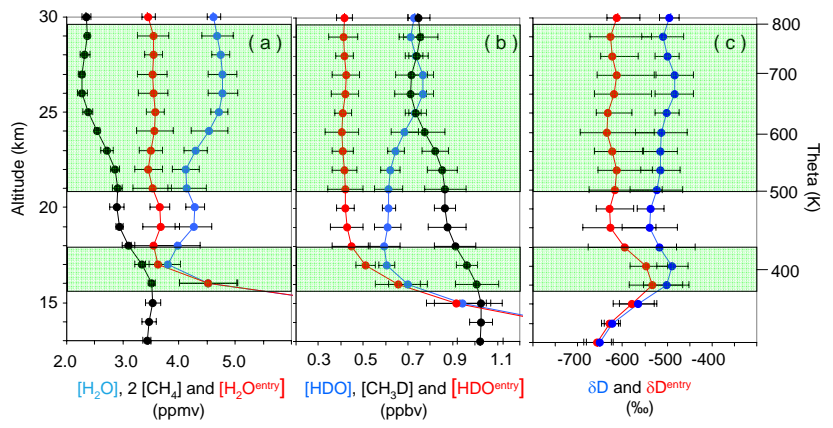

Fig. 1. Volume mixing ratio profiles of the trace gases measured, together with the derived stratospheric entry and entry delta values. The data shown are the results from a single balloon profile, launched at $33^{\circ} \mathrm{N}$ on 29 September 1996. The error bars give the $1 \sigma$ precision. The shaded areas denote the altitude regions used for the analysis, $380-425 \mathrm{~K}$ and $500-800 \mathrm{~K}$. The calculation of $\left[\mathrm{H}_{2} \mathrm{O}^{\text {entry }}\right],\left[\mathrm{HDO}^{\text {entry }}\right]$ and $\delta \mathrm{D}^{\text {entry }}$ is described in the text. (a) Mixing ratios of $\left[\mathrm{H}_{2} \mathrm{O}\right], 2\left[\mathrm{CH}_{4}\right]$ and $\left[\mathrm{H}_{2} \mathrm{O}^{\text {entry }}\right]$. (b) Mixing ratios of [HDO], $\left[\mathrm{CH}_{3} \mathrm{D}\right]$ and $\left[\mathrm{HDO}^{\text {entry }}\right]$. (c) Calculated delta values for $\delta \mathrm{D}$ and $\delta \mathrm{D}^{\text {entry }}$.

weighted by their individual precisions, which is estimated from the quality of the fits to the measured spectra using error propagation laws, as described in the supplement.

In the spectral microwindows chosen for analysis, the individual spectral lines of the different isotopes of interest do not overlap significantly, enabling a truly independent retrieval of each isotope.

Figure 1 shows a typical set of measured profiles and the corresponding calculated relative difference of the isotopic ratios, the delta values (see Eq. 2-5). Note that because of the long optical path through the atmosphere, small scale variations as observed in upper tropospheric air masses (Webster and Heymsfield, 2003) will be smoothed out.

The reported error in the retrieval of volume mixing ratio represents the relative precision of the retrieval at the corresponding levels. When calculating the ratio $\left[\mathrm{HDO}^{\text {entry }}\right] /\left[\mathrm{H}_{2} \mathrm{O}^{\text {entry }}\right]$ or $\delta \mathrm{D}^{\text {entry }}$ as shown in Fig. 1 the error bars have been calculated following the error propagation rules (see supplement http://www.atmos-chem-phys.net/ 10/201/2010/acp-10-201-2010-supplement.pdf). In order to achieve the required precision for the analysis, we average data (weighted by the precision on each level) in two separate layers, namely between 380 and $425 \mathrm{~K}$, and 500-800 K, reducing the uncertainties substantially.

\section{Isotopic fractionation in the stratosphere}

In the stratosphere, the total amount of hydrogen (i.e. $n(\mathrm{H}$, total $\left.)=2 n\left(\mathrm{H}_{2} \mathrm{O}\right)+4 n\left(\mathrm{CH}_{4}\right)+2 n\left(\mathrm{H}_{2}\right)\right)$ and deuterium (i.e. $n(\mathrm{D}$, total $\left.)=n(\mathrm{HDO})+n\left(\mathrm{CH}_{3} \mathrm{D}\right)+n(\mathrm{HD})\right)$ are effectively conserved within these six gases. Equation (2) can be modified to account for the chemical conversions between the trace gases and their isotopes. The volume mixing ratios of [HDO] and $\left[\mathrm{H}_{2} \mathrm{O}\right]$ at the tropopause, [HDO $\left.{ }^{\text {entry }}\right]$ and $\left[\mathrm{H}_{2} \mathrm{O}^{\text {entry }}\right]$, corrected for the chemical conversion in the stratosphere are given by (McCarthy et al., 2004; Rahn et al., 2003):

$$
\begin{aligned}
& {\left[\mathrm{HDO}^{\text {entry }}\right]=[\mathrm{HDO}]-\left(\left[\mathrm{CH}_{3} \mathrm{D}^{\mathrm{tr}}\right]-\left[\mathrm{CH}_{3} \mathrm{D}\right]\right)-\left(\left[\mathrm{HD}^{\mathrm{tr}}\right]-[\mathrm{HD}]\right)} \\
& {\left[\mathrm{H}_{2} \mathrm{O}^{\mathrm{entry}}\right]=\left[\mathrm{H}_{2} \mathrm{O}\right]-2\left(\left[\mathrm{CH}_{4}^{\mathrm{tr}}\right]-\left[\mathrm{CH}_{4}\right]\right)-\left(\left[\mathrm{H}_{2}^{\mathrm{tr}}\right]-\left[\mathrm{H}_{2}\right]\right)}
\end{aligned}
$$

The upper index tr stands for tropospheric values. $\left[\mathrm{H}_{2}\right]$ and [HD] cannot be measured in the infrared spectral region, but have been calculated using the correlations with $\left[\mathrm{CH}_{4}\right](\mathrm{Mc}-$ Carthy et al., 2004; Rahn et al., 2003). In the calculations for $\left[\mathrm{HDO}^{\text {entry }}\right]$ and $\left[\mathrm{H}_{2} \mathrm{O}^{\text {entry }}\right]$, the balloon-borne observations are complemented with the entry volume mixing ratios of methane and molecular hydrogen, and their deuterated isotopologues from tropospheric in-situ data of $\left[\mathrm{CH}_{4}^{\mathrm{tr}}\right]$, $\left[\mathrm{H}_{2}^{\mathrm{tr}}\right],\left[\mathrm{CH}_{3} \mathrm{D}^{\mathrm{tr}}\right]$ and $\left[\mathrm{HD}^{\mathrm{tr}}\right]$. This closure of the hydrogen and deuterium budget is possible because neither methane nor molecular hydrogen show significant fractionation during transport into the stratosphere. For $\left[\mathrm{CH}_{4}^{t r}\right]$ we take the global tropospheric values from the NOAA ESRL data base (ftp://ftp.cmdl.noaa.gov/ccg/). The trend in the isotopic ratios $\left[\mathrm{CH}_{3} \mathrm{D}^{\mathrm{tr}}\right] /\left[\mathrm{CH}_{4}^{\mathrm{tr}}\right]$ and $\left[\mathrm{HD}^{\mathrm{tr}}\right] /\left[\mathrm{H}_{2}^{\mathrm{tr}}\right]$ is $0.09 \% /$ year and $0.16 \% / y e a r$, respectively (Rhee et al., 2006). All entry volume mixing ratios are at the time of entry into the stratosphere, which is the date of measurement in the stratosphere, minus the age of air at the measured position. The age of air has been determined from the measured $\mathrm{CH}_{4}$ values as described in (Rahn et al., 2003). Having determined $\left[\mathrm{H}_{2} \mathrm{O}^{\text {entry }}\right]$, $\left[\mathrm{HDO}^{\text {entry }}\right]$, we finally can calculate $\delta \mathrm{D}^{\text {entry }}$ of water entering the stratosphere.

$\delta \mathrm{D}^{\text {entry }}=\frac{\left[\mathrm{HDO}^{\text {entry }}\right] /\left[\mathrm{H}_{2} \mathrm{O}^{\text {entry }}\right]}{\left([\mathrm{HDO}] /\left[\mathrm{H}_{2} \mathrm{O}\right]\right)_{\text {standard }}}-1$

where $\left([\mathrm{HDO}] /\left[\mathrm{H}_{2} \mathrm{O}\right]\right)_{\text {standard }}$ is SMOW expressed as volume mixing ratio. It may be important to emphasize that chemical processing in the stratosphere will change the concentration of the individual tracers, but does not affect the budget. Similarly, mixing processes do not affect the budget, but lead to smoothing (in time) of entry mixing ratio variations.

\section{Results}

To study processes that control $\delta \mathrm{D}^{\text {entry }}$ and $\left[\mathrm{H}_{2} \mathrm{O}^{\text {entry }}\right]$ in more detail, we separately analyze data from the lower stratosphere (380-425 K, $\sim 16-18 \mathrm{~km}$ altitude) and from the middle stratosphere $(500-800 \mathrm{~K}, \sim 21-30 \mathrm{~km}$ ) (Fig. 1). In the lower layer, relatively fast quasi-isentropic mixing and poleward transport occurs (Randel et al., 2004). Observations in this layer sample a mixture of air masses that recently (weeks to months) passed the tropopause, with comparatively large variability in $\left[\mathrm{H}_{2} \mathrm{O}^{\text {entry }}\right]$ and $\delta \mathrm{D}^{\text {entry }}$ due to variability in conditions at entry. Consequently, variations in the entry conditions on the timescale of weeks to months are still observable at this observation altitude. Conversely, measurements 


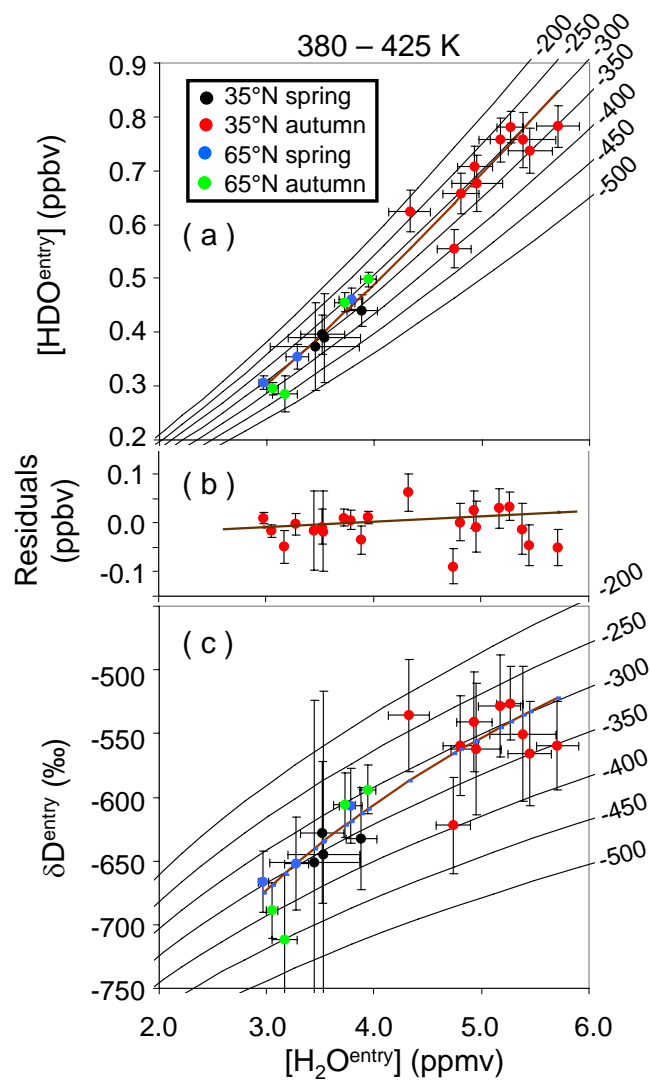

Fig. 2. Correlation plot of $\left[\mathrm{H}_{2} \mathrm{O}^{\text {entry }}\right]$ versus $\left[\mathrm{HDO}^{\text {entry }}\right]$ and $\delta \mathrm{D}^{\text {entry }}$ for the altitude range $380-425 \mathrm{~K}$. The different colours of the symbols in (a) and (c) correspond to the two latitudes $\left(35^{\circ} \mathrm{N}\right.$ and $65^{\circ} \mathrm{N}$ ) and the two seasons (spring and autumn) where the measurements have been performed. The error bars give the $1 \sigma$ precision. (a) $\left[\mathrm{H}_{2} \mathrm{O}^{\text {entry }}\right]$ versus $\left[\mathrm{HDO}^{\text {entry }}\right]$. The brown line is the weighted fit of the Rayleigh curve plus a linear term to the measured data. The set of calculated Rayleigh curves are given as black lines, ranging from $\delta \mathrm{D}=-200 \%$ o to $\delta \mathrm{D}=-500 \%$, as labelled on the right side of the Figure. (b) The residuals are measurements minus fit, where the fit is the sum of the Rayleigh curve plus a linear term to account for the ice contribution. The brown line shows this linear term. (b) The same expression as in (a), but expressed as $\left[\mathrm{H}_{2} \mathrm{O}^{\text {entry }}\right]$ versus $\delta \mathrm{D}^{\text {entry }}$.

in the upper layer are located in the well-mixed stratospheric "surf zone" (McIntyre and Palmer, 1984). As such, they exhibit both a much older mean age in the order of years and a broader age distribution, and provide low-pass (in time) filtered data of conditions at entry. Observations in the upper layer can resolve variability at entry on the timescales of years (i.e. one can observe interannual variability at entry in the upper layer), whereas in the lower layer one can observe seasonal and even sub-seasonal variability at entry.

\subsection{Short-term variability at 380-425 K}

Figure $2 \mathrm{a}$ shows the mixing ratio of $\left[\mathrm{HDO}^{\mathrm{entry}}\right]$ as a function of $\left[\mathrm{H}_{2} \mathrm{O}^{\text {entry }}\right]$ for all single balloon profiles, averaged in the $380-425 \mathrm{~K}$ layer. Figure $2 \mathrm{c}$ shows the same information, expressed as $\delta \mathrm{D}^{\text {entry }}$. The measurements show, as may be expected, a strong correlation between $\mathrm{HDO}$ and $\mathrm{H}_{2} \mathrm{O}$. We have calculated a set of Rayleigh fractionation curves (Johnson et al., 2001), black curves in Fig. 2a and c. The Rayleigh fractionation depends on the temperature and humidity (Keith, 2000; Johnson et al., 2001; Kaye, 1987). The Rayleigh curves have been calculated with the following initial conditions: $\left[\mathrm{H}_{2} \mathrm{O}\right]$ mixing ratio of $15 \mathrm{ppmv}$, and isotopic depletions ranging from $\delta \mathrm{D}=-200 \%$ (top curve in Fig. 2a) to $\delta \mathrm{D}=-500 \%$ (lowest curve) in steps of $\delta \mathrm{D}=50 \%$. The range of the initial conditions corresponds to the variations observed in the TTL (Moyer et al., 1996; Kuang et al., 2003; Webster and Heymsfield, 2003). Depending on the initial $\delta \mathrm{D}$, the Rayleigh fractionation curves follow different paths, but all exhibit similar slopes in the range of our $\left[\mathrm{H}_{2} \mathrm{O}^{\text {entry }}\right]$ data.

Given the strong evidence from the absolute $\delta \mathrm{D}$ depletion (i.e. the general isotopic enrichment compared to a Rayleigh process initialized in the boundary layer) that evaporating ice plays a significant role in the TTL water budget (Moyer et al., 1996), and the nearly constant isotopic depletion in profiles at a given time observed by ATMOS (Kuang et al., 2003), it is remarkable that the temporal variability at $380-425 \mathrm{~K}$ shows progressive isotopic depletion with lower water mixing ratios. Perhaps even more remarkable is the fact that the observations are close to the theoretical Rayleigh fractionation curves in the area of interest. Our data suggests the existence of an isotopic analogue to the water vapour tape recorder effect (Mote et al., 1996). Lack of detection in the ATMOS (Kuang et al., 2003) profiles may be due to insufficient accuracy and vertical resolution; more recent data from MIPAS indeed shows clear evidence for such seasonal variations (Steinwagner et al., 2007).

The measured data points have been fitted by a Rayleigh curve plus a linear term to account for other contributions such as ice. Since the physical relation between HDO $^{\text {entry }}$ and $\mathrm{H}_{2} \mathrm{O}^{\text {entry }}$ is given in Fig. $2 \mathrm{a}$ we fitted the data in Fig. 2a, but showed the results also in the commonly used delta notation (Fig. 2c). The solid brown line is the best fit, weighted by the individual $1 \sigma$ precision of the individual data points. The linear term of the fitted curve shows a marginal positive slope, which may be explained with a small contribution from isotopically heavy ice that increases with increasing $\mathrm{H}_{2} \mathrm{O}$.

Since it is not possible to derive the absolute amount of water entering as ice directly, we proceed as follows to estimate the seasonal trend in the contribution from ice. The total amount of $\mathrm{H}_{2} \mathrm{O}$ and $\mathrm{HDO}$ transported through the tropical tropopause can be expressed as a sum of gas phase water 
and ice.

$n\left(\mathrm{H}_{2} \mathrm{O}^{\text {total }}\right)=n\left(\mathrm{H}_{2} \mathrm{O}^{\text {gas }}\right)+n\left(\mathrm{H}_{2} \mathrm{O}^{\text {ice }}\right)$

$n\left(\mathrm{HDO}^{\mathrm{total}}\right)=n\left(\mathrm{HDO}^{\mathrm{gas}}\right)+n\left(\mathrm{HDO}^{\mathrm{ice}}\right)$

$\mathrm{H}_{2} \mathrm{O}$ and HDO are connected by the fractionation of the vapour and ice, respectively. We now interpret the observed data (i.e. the left hand sides of Eqs. 6 and 7) in terms of a vapour phase that follows strictly Rayleigh fractionation and ice with a constant isotopic depletion, that both passed the tropopause. The fractionation of the ice is not well constrained from observations; a sensible value is about $\delta \mathrm{D}^{\mathrm{ice}}=-300 \%$ (Webster and Heymsfield, 2003). In principle, we could solve Eqs. (6)-(7) to achieve the best fit with our measured total $n\left(\mathrm{H}_{2} \mathrm{O}^{\text {total }}\right)$ and $n\left(\mathrm{HDO}^{\text {total }}\right)$ data. The absolute partitioning between vapour and ice is not well constrained from our observations. However, we can estimate how much the contribution from ice varies as function of the vapour mixing ratio. For the Rayleigh curves calculated under conditions typical for the tropical tropopause (black lines in Fig. 2a and c) we find that for 5 ppmv total water, the ice contribution increases by $(0.1-0.7)$ ppmv, relative to the ice contribution at 2 ppmv total water. In other words, the observed $[\mathrm{HDO}]-\left[\mathrm{H}_{2} \mathrm{O}\right]$ slope can be understood as a linear combination from vapour and ice, and our data suggests that the ice contribution, $n\left(\mathrm{H}_{2} \mathrm{O}^{\text {ice }}\right)$ does not stay constant, but is positively correlated with the vapour phase $n\left(\mathrm{H}_{2} \mathrm{O}^{\text {gas }}\right)$.

To summarise, our data confirm previous findings of a strong isotopic enrichment of air entering the stratosphere $(\delta \mathrm{D}=-600 \%$ from our measurements to $\delta \mathrm{D}=-900 \%$ from pure Rayleigh fractionation), which may arise from evaporation of convectively lofted ice (Moyer et al., 1996; Kuang et al., 2003; Johnson et al., 2001; Payne et al., 2007; Nassar et al., 2007; Steinwagner et al., 2007). However, our data also yield a correlation of $\delta \mathrm{D}^{\text {entry }}$ with $\left[\mathrm{H}_{2} \mathrm{O}^{\text {entry }}\right]$ not seen in previous measurements. The slope of this correlation is close to that of Rayleigh fractionation, which suggests that in-situ dehydration plays an important role. But the observed slope, being slightly steeper than pure Rayleigh, implies that the amount of ice transported into the stratosphere is positively correlated with total $\left[\mathrm{H}_{2} \mathrm{O}^{\text {entry }}\right]$.

\subsection{Long-term variability at 500-800 K}

The interannual variability of $\delta \mathrm{D}^{\text {entry }}$ is estimated from the observations made at $500-800 \mathrm{~K}$ in well mixed stratospheric air. Since $\left[\mathrm{H}_{2} \mathrm{O}^{\text {entry }}\right]$ and $\delta \mathrm{D}^{\text {entry }}$ have been corrected for the tropospheric trends in $\mathrm{CH}_{4}$ and $\mathrm{H}_{2}$ and their isotopes, these measurements reveal the trend in the fractionation of water passing the tropopause. Figure 3 shows the averages of $\left[\mathrm{H}_{2} \mathrm{O}\right],[\mathrm{HDO}]$, and $\delta \mathrm{D}^{\text {entry }}$ (or the ratio $\left.\left[\mathrm{HDO}^{\text {entry }}\right] /\left[\mathrm{H}_{2} \mathrm{O}^{\text {entry }}\right]\right)$ at $500-800 \mathrm{~K}$ as a function of year. Dehydration in the arctic vortex could affect isotopic depletion of water in a poorly constrained way. Hence, the data measured at $65^{\circ} \mathrm{N}$ are shown, but not included in

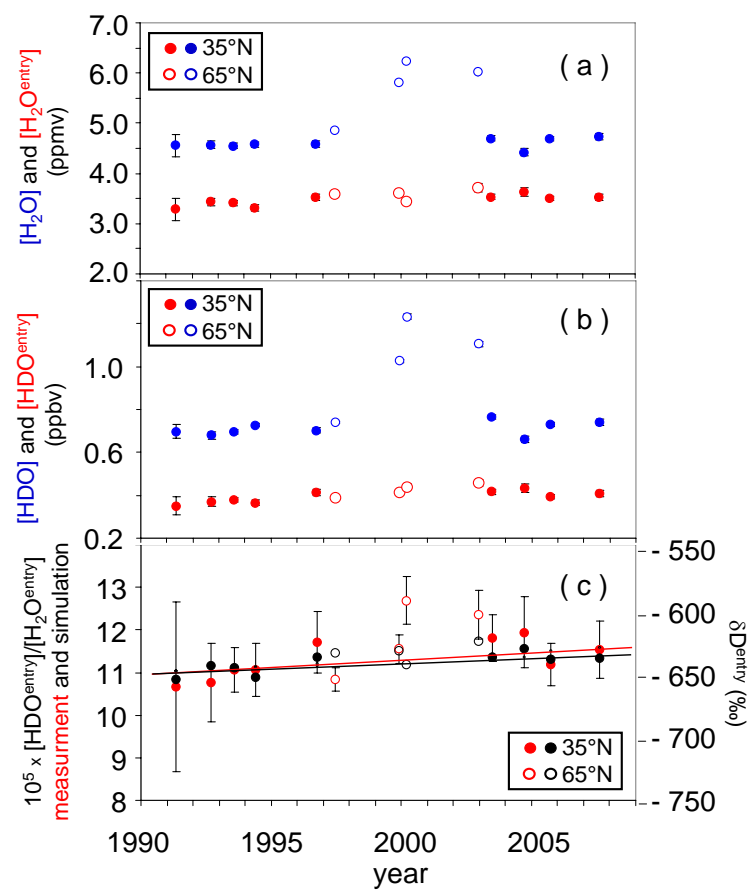

Fig. 3. Measured and simulated $\left[\mathrm{H}_{2} \mathrm{O}^{\text {entry }}\right]$, $\left[\mathrm{HDO}^{\text {entry }}\right]$ and $\delta \mathrm{D}^{\text {entry }}$ as a function of year together with their calculated trends at $500-800 \mathrm{~K}$. The closed symbols show the data measured at $35^{\circ} \mathrm{N}$, the open symbols give the data at $65^{\circ} \mathrm{N}$. The error bars for the measurements give the $1 \sigma$ precision. (a) Variability of measured $\left[\mathrm{H}_{2} \mathrm{O}\right]$ (blue) and $\left[\mathrm{H}_{2} \mathrm{O}^{\text {entry }}\right]$ (red). (b) Variability of measured [HDO] (blue) and [HDO $\left.{ }^{\text {entry }}\right]$ (red). (c) Measured (red) ratio $\left[\mathrm{HDO}^{\text {entry }}\right] /\left[\mathrm{H}_{2} \mathrm{O}^{\text {entry }}\right]$ (left scale) or expressed as $\delta \mathrm{D}^{\text {entry }}$ (right scale). The black symbols give the simulated data. The red line give the linear fits to the measured data at $35^{\circ} \mathrm{N}$, the black one the linear fit to the simulated data at $35^{\circ} \mathrm{N}$.

the following analysis. A linear fit (red line in Fig. 3) through the measured $\delta \mathrm{D}^{\text {entry }}$ (weighted by the individual $1 \sigma$ precision) yields a weak trend in the delta values of $(11.1 \pm 12.3) \%$ o/decade ( $1 \sigma$ precision) of water entering the stratosphere for the period 1991-2007. This isotopic enrichment may be a consequence of changes in the fractionation of vapour or ice entering the stratosphere, or in the partitioning between these two sources. In the following, we determine the trend in particulate water that is not correlated with variations in vapour entry mixing ratios.

\section{Trend in particulate water}

Although the trend in $\delta \mathrm{D}^{\text {entry }}$ of $(11.1 \pm 12.3) \%$ o/decade is statistically not significant, out data allow calculate an upper limit for the trend in particulate water transported through the tropopause. The measured correlation of the seasonal variabilities of [ $\left.\mathrm{HDO}^{\text {entry }}\right]$ to $\left[\mathrm{H}_{2} \mathrm{O}^{\text {entry }}\right]$ at $380-425 \mathrm{~K}$ (black line in Fig. 2) allows calculating $\delta \mathrm{D}^{\text {entry }}$ at $500-800 \mathrm{~K}$ for the measured $\left[\mathrm{H}_{2} \mathrm{O}^{\text {entry }}\right]$ at $500-800 \mathrm{~K}$. This gives calculated 
values for $\delta \mathrm{D}^{\text {entry }}$ at $500-800 \mathrm{~K}$ under the hypothesis that interannual variability is governed by the same processes as the variability on shorter timescales, which we have shown to be consistent with temperature dependent Rayleigh fractionation plus a seasonal dependent ice contribution. The linear fit through these predictions (black line in Fig. 3) yields a trend of $10.5 \%$ o/decade, which is statistically not significantly different from the observed trend. Hence, our data shows a tendency for isotopic enrichment over the period of observation, but there is no indication that the contribution from ice would have changed (as may be expected due to trends in aerosol loading) in a manner other than that seen in short term variations.

Our findings do not depend on assumptions on the tropopause temperature trend. Furthermore, our data interpretation depends only on the slopes of the curves in Figs. 2 and 3, but not on their absolute values. Changing the strength of the spectral lines for the retrieval within realistic limits $( \pm 10 \%)$ causes a bias in the absolute values of the delta values, but does not affect the slopes. Changing the tropospheric trends of $\mathrm{CH}_{4}, \mathrm{H}_{2}$ and their isotopologues $\mathrm{HD}$ and $\mathrm{CH}_{3} \mathrm{D}$ within realistic limits $( \pm 20 \%)$ changes the slope of the delta values by $\pm 2 \%$ /decade, which is within the uncertainties of the slopes. Changing the age-of-air within realistic limits $( \pm 20 \%$ ) changes the slope by $\pm 2 \%$ odecade, also within the uncertainties of the slopes.

The long-term change in the amount of ice transported through the tropopause that is not predicted from the shortterm variations can be calculated in a similar way as described in Sect. 4.1. Assuming a mean mixing ratio of water vapour transported through the tropopause of about 3-4 ppmv (Fueglistaler et al., 2005; Lambert et al., 2007) and $\delta \mathrm{D}=-300 \%$ o for convectively lofted ice (Webster and Heymsfield, 2003) the $(0.6 \pm 12.3) \%$ o/decade deviation between the observed and predicted trends in $\delta \mathrm{D}^{\text {entry }}$ converts to an increase in the amount of ice delivered to the stratosphere of $(0.01 \pm 0.13) \mathrm{ppmv} /$ decade. Note that these results are relatively insensitive to the exact value of water entering the stratosphere, but are sensitive to $\delta \mathrm{D}$ of ice entering the stratosphere. The closer the isotopic composition of this "additional" ice is to that of the average total water entering the stratosphere, the less sensitive is our method. In the (unrealistic) case where the isotopic composition of the vapour and ice would be identical, it would not be possible to measure an effect from ice evaporation on $\delta \mathrm{D}$.

We also checked the hypothesis that the observed $\delta \mathrm{D}$ trend arises solely from ice, which means we completely ignore the observed [ $\left.\mathrm{HDO}^{\text {entry }}\right]:\left[\mathrm{H}_{2} \mathrm{O}^{\text {entry }}\right]$ relation at $380-425 \mathrm{~K}$ (Fig. 2). Assuming again ice clouds of $\delta \mathrm{D}=-300 \%$, this yields an upper limit of $\left[\mathrm{H}_{2} \mathrm{O}^{\text {ice }}\right]$ of $0.12 \mathrm{ppmv} /$ decade for convectively lofted ice.

Because of the broad age spectrum in the layer of 500$800 \mathrm{~K}$, we expect that seasonal effects in the fractionation should be marginal. Taking only the autumn flights (reducing the number of data points and increasing the uncertainty) for the calculation above gives an increase in the measured delta values of $\delta \mathrm{D}=(8.0 \pm 13.5) \%$ o/decade and of $\delta \mathrm{D}=4.3 \%$ o/decade for the predicted one. The difference in these trends of $\delta \mathrm{D}=(3.7 \pm 13.5) \%$ o/decade corresponds to an increase in ice of $(0.04 \pm 0.16) \mathrm{ppmv} / \mathrm{dec}$ ade, only slightly larger than the value from above.

\section{Conclusions}

Together, the seasonal and interannual changes in $\delta \mathrm{D}^{\text {entry }}$ suggest that between 1991 and 2007 the contribution from changes in particulate water transported through the tropopause plays only a minor role in altering in the amount of water entering the stratosphere. The changes in the calculated amount of particulate water are within the uncertainty of model studies of stratospheric water that ignore the contribution of particulate water (Fueglistaler and Haynes, 2005). Moreover, they are about an order of magnitude smaller than what would be required for a trend of the magnitude as proposed (Rosenlof et al., 2001).

Acknowledgements. This research was financially supported by the EU-project SCOUT and by the national Helmholtz Association within the virtual institute PEP. We gratefully acknowledge Robert Toth (JPL/NASA, Pasadena) for updates of the $\mathrm{H}_{2} \mathrm{O}$ and HDO spectral line list. We thank the Columbia Scientific Balloon Facility (CSBF) who launched the balloons from which the MkIV data were acquired and the financial support from NASA. We acknowledge Jean-Francois Blavier, Bhaswar Sen, and David Petterson of JPL for their various contributions to the JPL MkIV instrument.

Edited by: J. Kaiser

\section{References}

Brewer, A. W.: Evidence for a world circulation provided by the measurements of helium and water vapour distribution in the stratosphere, Q. J. Roy. Meteor. Soc., 75, 351-363, 1949.

Brasseur, G. P. and Solomon, S.: Aeronomy of the middle atmosphere, Atmospheric and oceanographic sciences library, Springer, Netherlands, 2005.

Forster, P. M. F. and Shine, K. P.: Assessing the climate impact of trends in stratospheric water vapor, Geophys. Res. Lett., 29, 1086, doi:10.1029/2001GL013909, 2002.

Fueglistaler, S. and Haynes, P. H.: Control of interannual and longer-term variability of stratospheric water vapour, J. Geophys. Res. 110, D24108, doi:10.1029/2005JD006019, 2005.

Fueglistaler, S., Bonazzola, M., Haynes, P. H., and Peter, T.: Stratospheric water vapor predicted from the Lagrangian temperature history of air entering the stratosphere in the tropics, J. Geophys. Res., 110, D08107, doi:10.1029/2004JD005516, 2005.

Fueglistaler S., Dessler, A. E., Dunkerton, T. J., Folkins, I., Fu, Q., and Mote, P. W.: Tropical tropopause layer, Rev. Geophys., 47, RG1004, doi:10.1029/2008RG000267, 2009.

Holton, J. R., Haynes, P. H., McIntyre, M. E., Douglass, A. R., Rood, R. B., and Pfister, L.: Stratosphere-troposphere exchange, Rev. Geophys., 33, 403-440, doi:10.1029/95RG02097, 1995. 
Jensen, E. and Pfister, L.: Transport and freeze-drying in the tropical tropopause layer, J. Geophys. Res., 109, D02207, doi:10.1029/2003JD004022, 2004.

Johnson, D. G., Jucks, K. W., Taub, W. A., and Chance, K. V.: Isotopic composition of stratospheric water vapor: Implications for transport, J. Geophys. Res., 106, 12219-12226, 2001.

Kaye, J. A.: Mechanisms and Observations for Isotope Fractionation of Molecular Species in Planetary Atmospheres, Rev. Geophys., 25, 1609-1658, 1987.

Keith, D. W.: Stratosphere-troposphere exchange: Inferences from the isotopic composition of water vapor, J. Geophys. Res., 105, 15167-15173, 2000.

Kuang, Z., Toon, G. C., Wennberg, P. O., and Yung, Y. L.: Measured $\mathrm{HDO} / \mathrm{H}_{2} \mathrm{O}$ ratios across the tropical tropopause, Geophys. Res. Lett., 30, 1372, doi:10.1029/2003GL017023, 2003.

Lambert, A., Read, W. G., Livesey, N. J., et al.: Validation of the Aura Microwave Limb Sounder middle atmosphere water vapor and nitrous oxide measurements, J. Geophys. Res. 112, D24S36, doi:10.1029/2007JD008724, 2007.

McCarthy, M. C., Boering, K. A., Rahn, T., Eiler, J. M., Rice, A. L., Tyler, S. C., Schauffler, S., Atlas, E., and Johnson, D. G.: The hydrogen isotopic composition of water vapor entering the stratosphere inferred from high-precision measurements of DD-CH 4 and DD-H 2 , J. Geophys. Res. 109, D07304, doi:10.1029/2003JD004003, 2004.

McIntyre, M. E. and Palmer, T. N.: The "surf zone" in the stratosphere, J. Atmos. Terr. Phys., 46, 825-849, 1984.

Mote, P. W., Rosenlof, K. H., McIntyre, M. E., Carr, E. S., Gille, J. C., Holton, J. R., Kinnersley, J. S., Pumphrey, H. C., Russell III, J. M., and Waters, J. W.: An atmospheric tape recorder: The imprint of tropical tropopause temperatures on stratospheric water vapour, J. Geophys. Res., 101, 3989-4006, doi:10.1029/95JD03422, 1996.

Moyer, E. J., Irion, F. W., Yung, Y. L., and Gunson, M. R.: ATMOS stratospheric deuterated water and implications for tropospherestratosphere transport, Geophys. Res. Lett., 23, 2385-2388, 1996.

Nassar, R., Bernath, P. F., Boone, C. D., Gettelman, A., McLeod, S. D., and Rinsland, C. P.: Variability in $\mathrm{HDO} / \mathrm{H}_{2} \mathrm{O}$ abundance ratios in the tropical tropopause layer, J. Geophys. Res., 112, D21305, doi:10.1029/2007JD008417, 2007.

Notholt, J., Luo, B. P., Fueglistaler, S., Weisenstein, D., Rex, M., Lawrence, M. G., Bingemer, H., Wohltmann, I., Corti, T., Warneke, T., von Kuhlmann, R., Peter, T.: Influence of tropospheric $\mathrm{SO}_{2}$ emissions on particle formation and the stratospheric humidity, Geophys. Res. Lett., 32, L07810, doi:10.1029/2004GL022159, 2005.

Notholt, J., Toon, G. C., Jones, N., Griffith, D., and Warneke, T.: Spectral line finding program for atmospheric remote sensing using full radiation transfer, J. Quant. Spectrosc. Ra., 97, 112-115, 2006.

Oltmans, S. J. and Hofmann, D. F.: Increase in lower-stratospheric water vapour at a mitlatitude N.H. site from 1981 to $1994, \mathrm{Na}-$ ture, 374, 146-149, 1995.

Payne, V. H., Noone, D., Dudhia, A., Piccolo, C., and Grainger, R. G.: Global satellite measurements of HDO and implications for understanding the transport of water vapour into the stratosphere, Q. J. Roy. Meteor. Soc., 133, 1459-1471, 2007.
Rahn, T., Eiler, J. J., Boering, K. A., Wennberg, P. O., McCarthy, M. C., Tyler, S., Schauffler, S., Donnelly, S., and Atlas, E.: Extreme deuterium enrichment in stratospheric hydrogen and the global atmospheric budget of $\mathrm{H}_{2}$, Nature, 424, 918-921, 2003.

Randel, W. J., Wu, F., Oltmans, S. J., Rosenlof, K. H., and Nedoluha, G. E.: Interannual changes of stratospheric water vapor and correlations with tropical tropopause temperatures, J. Atmos. Sci., 61, 2133-2148, 2004.

Randel, W. J., Wu, F., Vömel, H., Nedoluha, G. E., and Forster, P.: Decreases in stratospheric water vapor after 2001: Links to changes in the tropical tropopause and the Brewer-Dobson circulation, J. Geophys. Res., 111, D12312, doi:10.1029/2005JD006744, 2006.

Read, W. G., Schwartz, M. J., Lambert, A., Su, H., Livesey, N. J., Daffer, W. H., and Boone, C. D.: The roles of convection, extratropical mixing, and in-situ freeze-drying in the Tropical Tropopause Layer, Atmos. Chem. Phys., 8, 6051-6067, 2008, http://www.atmos-chem-phys.net/8/6051/2008/.

Rhee, T. S., Brenninkmeijer, C. A., Brass, M., Roeckmann, T., Langenfelds, R., Steele, P., and Fraser, P.: The Increasing Trend of Deuterium in Atmospheric $\mathrm{H}_{2}$ and $\mathrm{CH}_{4}$ Based on Cape Grim Air Archive, talk No. 9292 presented at the AGU fall meeting 2006, San-Francisco, USA, 11-15, December 2006.

Rosenlof, K. H., Oltmans, S. J., Kley, D., Russell III, J. M., Chiou, E.-W., Chu, W. P., Johnson, D. G., Kelly, K.-K., Michelsen, H. A., Nedoluha, G. E., Remsberg, E. E., Toon, G. C., and McCormick, M. P.: Stratospheric water vapor increases over the past half-century, Geophys. Res. Lett., 28, 1195-1198, 2001.

Rothman, L. S., Jacquemart, D., Barbe, A., et al.: The HITRAN 2004 molecular spectroscopic database, J. Quant. Spectrosc. Ra., 96, 139-204, 2005.

Scherer, M., Vömel, H., Fueglistaler, S., Oltmans, S. J., and Staehelin, J.: Trends and variability of midlatitude stratospheric water vapour deduced from the re-evaluated Boulder balloon series and HALOE, Atmos. Chem. Phys., 8, 1391-1402, 2008, http://www.atmos-chem-phys.net/8/1391/2008/.

Sherwood, S.: A microphysical connection among biomass burning, cumulus clouds, and stratospheric moisture, Science, 295 , 1272-1275, 2002.

Sen, B., Toon, G. C., Blavier, J.-F., Fleming, E. L., and Jackman, C. H.: Balloon-borne observations of midlatitude fluorine abundance, J. Geophys. Res., 101, 9045-9054, 1996.

Steinwagner, J., Milz, M., von Clarmann, T., Glatthor, N., Grabowski, U., Höpfner, M., Stiller, G. P., and Röckmann, T.: HDO measurements with MIPAS, Atmos. Chem. Phys., 7, 26012615, 2007, http://www.atmos-chem-phys.net/7/2601/2007/.

Toon, G. C.: The Jet Propulsion Laboratory MkIV Interferometer, Opt. Photonics News, 2, 19-21, 1991.

Webster, C. R. and Heymsfield, A. J.: Water Isotope Ratios D/H, ${ }^{18} \mathrm{O} /{ }^{16} \mathrm{O},{ }^{17} \mathrm{O} /{ }^{16} \mathrm{O}$ in and out of Clouds Map Dehydration Pathways, Science, 302, 1742-1745, 2003.

Weinstock, E. M., Hintsa, E. J., Dessler, A. E., and Anderson, J. G.: Measurements of Water Vapor in the Tropical Lower Stratosphere During the CEPEX Campaign: Results and Interpretation, Geophys. Res. Lett., 22, 3231-3234, 1995.

Zhou, X.-L., Geller, M. A., and Zhang, M.: Cooling trend of the tropical cold point tropopause temperatures and its implications, J. Geophys. Res., 106, 1511-1522, 2001. 